\title{
The Glymphatic System: A Review
}

\section{O sistema glinfático: revisão}

\author{
Louise Makarem Oliveira ${ }^{1}$ Eberval Gadelha Figueiredo ${ }^{2}$ Carlos Michel Albuquerque Peres ${ }^{3}$
}

${ }^{1}$ Faculty of Medicine, Universidade Federal do Amazonas, Manaus, AM, Brazil

Address for correspondence Carlos Michel Albuquerque Peres, MD,

2 Department of Neurosurgery, Faculdade de Medicina, Universidade PhD, Hospital Santa Julia, Avenida Boulevard Álvaro Maia 510 - Centro, de São Paulo, São Paulo, SP, Brazil

${ }^{3}$ Neurosurgery Service, Hospital Santa Julia, Manaus, AM, Brazil

Arq Bras Neurocir 2018;37:190-195.

\section{Abstract \\ Keywords \\ - glymphatic system \\ - metabolite clearance \\ - central nervous system \\ - brain metabolism}

\section{Resumo}

The brain represents $\sim 2 \%$ of the adult body mass; conversely, it is responsible for $20 \%$ to $25 \%$ of the glucose and $20 \%$ of the oxygen consumption, receiving $15 \%$ of the cardiac output. This substantial metabolic rate is associated with a significant production of biological debris, which is potentially toxic. Therefore, a complex and efficient clearance system is required to prevent the accumulation of byproducts and ensure optimal function. However, until today, there is little knowledge about this topic. The glymphatic system, also known as perivascular pathway, is a recently described glialdependent network that is responsible for the clearance of metabolites from the central nervous system (CNS), playing a role equivalent to the one played by the lymphatic vessels present in other organs. Studies have demonstrated that the glymphatic pathway has a paramount role in protein homeostasis, and that the malfunction of this system may be related to the development of neurodegenerative disorders such as Alzheimer disease and normal pressure hydrocephalus. They also showed that body posture, exercise and the state of consciousness influence the glymphatic transport. In this context, the understanding of this clearance system could not only clarify the pathophysiology of several diseases, but also contribute to future therapeutic interventions. In the present article, we will evaluate the glymphatic pathway, focusing on the factors that regulate its flow, as well as on its role in CNS physiology and in disease initiation and progression, including dementia, hydrocephalus, glaucoma and traumatic brain injury. Ultimately, this review also aims to encourage further research on novel therapeutic targets.

O cérebro representa cerca de $2 \%$ da massa corporal de um adulto; contrariamente, é responsável por entre $20 \%$ e $25 \%$ do consumo de glicose, e $20 \%$ do consumo de oxigênio, respectivamente. Essa taxa metabólica substancial está associada à produção elevada de detritos biológicos, potencialmente tóxicos. Desse modo, um sistema de depuração complexo e eficiente faz-se necessário para prevenir o acúmulo de subprodutos e assegurar função ideal. No entanto, até os dias atuais, há pouco conhecimento acerca desse tópico. O sistema glinfático, também conhecido como received January 28, 2018 accepted June 11, 2018 published online July 27, 2018
DOI https://doi.org/ $10.1055 / \mathrm{s}-0038-1667052$ ISSN $0103-5355$.
Copyright $\odot 2018$ by Thieme Revinter

Publicações Ltda, Rio de Janeiro, Brazil
License terms

(요 (1) $\Theta \circledast$ 


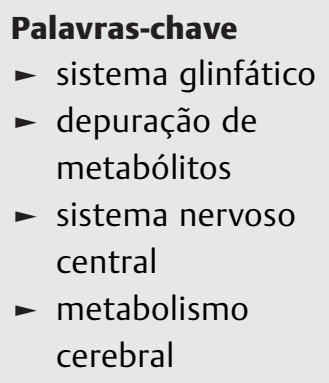

via perivascular, é uma rede dependente de células da glia recentemente descrita, que é responsável pela depuração de metabólitos do sistema nervoso central (SNC), à semelhança dos vasos linfáticos presentes em outros órgãos. Estudos demonstraram que a via glinfática tem um papel fundamental na homeostase proteica, podendo sua disfunção ser associada ao desenvolvimento de transtornos neurodegenerativos, como a doença de Alzheimer e a hidrocefalia de pressão normal. Do mesmo modo, esses estudos demonstraram que a postura corporal, o exercício e o estado de consciência influenciam no transporte glinfático. Nesse contexto, o entendimento do sistema de depuração cerebral pode não só esclarecer a fisiopatologia de diversas doenças, como também contribuir para intervenções futuras. Neste artigo, revisaremos a via glinfática, focando em fatores que regulam o seu fluxo, e em seu papel na fisiologia do SNC e na iniciação e progressão de doenças, incluindo demência, hidrocefalia de pressão normal, glaucoma e traumatismo cranioencefálico. Por fim, esta revisão também visa estimular pesquisas sobre novos alvos terapêuticos.

\section{Introduction}

Lymphatic vessels are distributed all over the peripheral tissues, playing an important role in the removal of potentially toxic metabolic products, and representing the principal mean through which fluid excess and proteins from the interstitial spaces are transported to the blood. Albeit the density of these vessels relates to each tissue's metabolic rate, the central nervous system (CNS), which is responsible for over $20 \%$ of the body's metabolism, apparently lacks such structures. ${ }^{1}$

Formed by the end-feet of astrocytes and capillary endothelial cells with tight junctions and almost no pores, the blood-brain barrier (BBB) prevents the generation of an ultrafiltrate. ${ }^{2}$ Although one could advocate that this justifies the absence of a lymphatic system, ${ }^{2}$ the need to remove toxic substances and macromolecules still relies on an efficient clearance pathway.

It has long been known that the blood vessels of the brain and the spinal cord are surrounded by perivascular spaces. These vessels have an inner wall made of the surface of vascular cells and an outer wall made of the end-feet of astrocytes, which are extensions that branch out from the glial cells. The function of these spaces, however, remained a mystery for years. ${ }^{3}$ In the 1970 s, it was documented that extracellular solutes administered into the brain parenchyma of a rat were transported faster than it could be explained by diffusion and established drainage pathways. ${ }^{2,4}$ Almost a decade later, the perivascular channels became a focus of investigation, and rapid (4-10 minutes) periarterial influx of horseradish peroxidase injected in the subarachnoid space of mammals was demonstrated by Rennels and his team. ${ }^{5}$ This research also claimed that highlighted arterial pulsations acted as a convective driver of the protein in the cerebrospinal fluid (CSF). ${ }^{2,5}$ In 2012, Iliff and Nedergaard used fluorescent tracers of contrasting molecular weight to reproduce Rennels' experiment. They applied the substance into the CSF of mice, via either the cisterna magna or the lateral ventricles, and noticed both a slow absorption into the parenchyma from the ventricles and a fast influx into the periarterial spaces when the tracers were administered into the cisterna. Furthermore, this study differentiated arteries and veins, enabling the understanding that dyes were transported along periarterial, but not perivenous spaces, and showing that while a physical barrier formed by the end-feet of the astrocytes trapped larger molecules, the smaller ones escaped from the periarterial spaces. $2,6,7$

Other studies by Illif and coworkers analyzed both the behavior of the functioning CNS when amyloid- $\beta$ 1-40 (A $\beta 1-40)$ was injected into the brain parenchyma, and the importance of aquaporin-4 (AQP4) water channels for solute drainage and CSF transportation. The results revealed that the elimination of $A B 1-40$ occurred partly through the perivenous spaces, and that genetic deletion of AQP4 led to a significantly reduced glymphatic clearance. ${ }^{2,6,7}$ In 2016, a study conducted by Murlidharan evidenced parenchymal retention of adenoassociated viruses in aging mice, coinciding with AQP4 channel polarization loss, reinforcing the importance of aquaporins. ${ }^{8}$

This review is a summary of the current and past information on the glymphatic system, aiming to report what is known about the pathway's anatomy, histology, physiology and malfunction, and to assess its regulation factors and highlight important topics of discussion related to neurological disorders and their treatment.

\section{The Glymphatic System}

Each one of these findings helped define what is now known as the "glymphatic system," a clearance pathway that comprises a network of periarterial and perivenous AQP4-dependent conduits. Nedergaard and Goldman named the system, combining the words glia - a type of brain cell, such as the astrocytes - and lymphatic - referring to the pathway's function. ${ }^{3}$

Macroscopically, the CSF produced by the choroid plexus within the ventricles moves from the lateral ventricles into the third ventricle via the interventricular foramen, and then flows to the fourth ventricle via the cerebral aqueduct. Afterwards, the CSF can either remain in the ventricular system and flow through the spinal canal, or flow out into the subarachnoid 


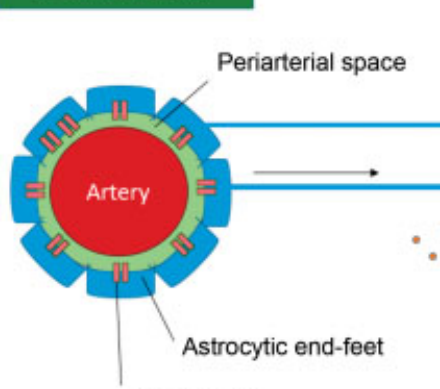

Aquaporin-4

Fig. 1 Overview of the cerebrospinal and interstitial fluid through the glymphatic system. The cerebrospinal fluid (CSF) flows into the brain within the perivascular Virchow-Robin spaces surrounding arteries, driving the interstitial waste into the perivenous spaces. This process depends on aquaporin-4 (AQP4), which is abundant in the astrocytic end-feet that circumscribe both arteries and veins.

space (SAS) via the foramina of Luschka (lateral) and Magendie (medial), being later absorbed by the arachnoidal villi.

Microscopically, however, a new glymphatic flow was described (-Fig. 1). According to this model, the CSF enters the brain through the perivascular Virchow-Robin spaces surrounding the arteries from the subarachnoid space, ${ }^{9}$ passing into the interstice via the astrocytic AQP4 (abundant in astrocytic end-feet), which line these arteries and arterioles. Subsequently, the CSF enters the brain parenchyma, a process driven by diffusion, convection and local mixing with the interstitial fluid (ISF). The resulting CSF-ISF exits the interstitial space (ISP) through the AQP4 channels lining the Virchow-Robin spaces surrounding the veins. ${ }^{2,3,6,7}$

\section{Results}

\section{Influencing Factors}

It has been demonstrated that many factors influence the glymphatic transport. Among them, the neuroinflammation associated with aging, the brain's arousal level, body posture and voluntary exercise stand out. In this section, we evaluate each of these factors. - Table 1 shows a summary of the main implications of these factors to the glymphatic system.

\section{Aging}

Aging is characterized by chronic, low-grade inflammation, ${ }^{10}$ which neurologically expresses itself through the activation of microglia and astrocytes, resulting in altera- tions in morphology and function, thus leading to cognitive impairment. ${ }^{11,12}$ The AQP4, which is essential to the proper function of the glymphatic via, relocates from the feet to the somata of the astrocytes, impairing the function of the system by preventing CSF-ISF perivascular exchange. ${ }^{13}$

Neuroinflammation is also associated with protein misbalance. ${ }^{14}$ As glymphatic homeostasis is lost, aberrant accumulation of waste products occurs; among these waste products, hyperphosphorylated and misfolded proteins stand out., 3,16 Intracellular processes, including proteasomal degradation and autophagy, are often enough to remove such substances without further repercussion. ${ }^{1}$ However, that does not fully justify the waste clearance mechanisms, as it is undisputed that some proteins are released into the interstitial fluid.

Moreover, arterial pulsations, essential to CSF movement, ${ }^{17}$ are reduced in elderly patients, resulting in a progressively impaired glymphatic transport. ${ }^{18}$ These facts partially explain why neurodegenerative diseases such as Alzheimer usually affect the elderly.

\section{Sleep}

Sleep is known to be restorative, but the reason behind this concept has not been fully disclosed. On 2013, Xie et al investigated the impact of sleep on the behavior of the glymphatic system, using in vivo two-photon imaging to compare CSF influx into the cortex of anesthetized, awake, and sleeping mice. This study confirmed that sleeping plays a vital role in the efficiency of metabolite clearance, with the

Table 1 Factors that influence the glymphatic system and their main implications

\begin{tabular}{|l|l|}
\hline Influencing factors & Glymphatic system implication \\
\hline Aging & $\begin{array}{l}\text { Aging leads to neuroinflammation, which is associated with protein imbalance. } \\
\text { The glymphatic system is also less efficient in the elderly due to a reduction in arterial pulsations }\end{array}$ \\
\hline Sleep & The glymphatic parthway is responsible for $40 \%$ of the total amyloid- $\beta$ clearance during sleep \\
\hline Body posture & Glymphatic transport and amyloid- $\beta$ clearance are higher in the lateral and supine positions \\
\hline Voluntary exercise & $\begin{array}{l}\text { Voluntary running diminishes amyloid- } \beta \text { deposit and attenuates the inflammatory } \\
\text { activation of glial cells }^{25}\end{array}$ \\
\hline
\end{tabular}


glymphatic pathway being responsible for $40 \%$ of the total $A B$ clearance during sleep. ${ }^{19}$ This discovery reinforces the idea that continued lack of sleep can lead to cognition impairment, seizures, dementia, and even death. ${ }^{20,21}$ Similarly, during anesthesia, the interstitial space of the brain also expands when compared to its size during the awake state, suggesting that it is not the circadian rhythm but the arousal level that determines volume alterations and subsequent clearance efficacy. ${ }^{19}$

\section{Body Posture}

In 2015, Lee and Xie et al evaluated the influence of body posture on the glymphatic pathway of the brain. They advocated that cerebral hemodynamics and intracranial pressures were highly influenced by body posture. ${ }^{22,23}$ Glymphatic transport and $A \beta$ clearance are higher in the lateral and supine positions. ${ }^{24}$

\section{Voluntary Exercise}

In 2017, He et al determined the effects of voluntary exercise on glymphatic clearance of $A \beta$ and on neuroinflammation by assessing aging mice. According to their findings, voluntary running diminishes the deposit of $A B$, therefore restoring protein homeostasis, and it also attenuates the inflammatory activation of glial cells. Overall, glymphatic clearance was optimized by exercise, which clinically reflected on cognitive improvement. $^{25}$

\section{Diseases}

The role of the glymphatic pathway on several neurological diseases is an important research topic. The system is especially linked to neurodegenerative disorders, such as Alzheimer disease, normal pressure hydrocephalus, glaucoma and traumatic brain injury. In - Table 2 the glymphatic pathway malfunction related to these diseases is summarized.

\section{Alzheimer Disease}

Alzheimer disease, the leading cause of dementia, is histologically characterized by tau and $A \beta$ accumulation. ${ }^{26}$ Whereas the former protein is brain-specific microtubule-associated, the latter is a proteolytic fragment of the transmembrane amyloid precursor. ${ }^{27}$ As aforementioned, aging is associated with various alterations that ultimately lead to glymphatic impairment, and, thus, to $A \beta$ accumulation.
Strategies that improve, or even restore, proper waste clearance have a promising role in preventing or delaying the onset of Alzheimer disease. A study by Ren et al showed that n-3 polyunsaturated fatty acids (PUFAs) significantly promote extracellular $A \beta$ clearance from the brain. The study linked the result to the AQP4- dependent glymphatic system, as such beneficial effects were absent in AQP4-knockout mice. $^{13}$ This research also demonstrated that n-3 PUFAs markedly inhibit the activation of astrocytes and protect the AQP4 polarization in the affected brain region after $A B$ injection.

Despite the efforts to find a drug that enhances $A \beta$ clearance, positively affecting those suffering from Alzheimer disease, a double-blind, placebo-controlled phase 3 trial published in the New England Journal of Medicine in 2018 reported no benefits after the administration of solanezumab, a humanized monoclonal antibody designed to increase $A B$ brain clearance. $^{28}$

\section{Normal Pressure Hydrocephalus}

The CSF flow is dependent on the cardiac cycle. The brain and intracranial vasculature expand and compress the lateral and third ventricles during the systole, forcing the CSF to flow caudally. Conversely, they contract during the diastole, so the movement through the cerebral aqueduct reverses. ${ }^{9}$

Once arterial pulsations power the CSF flow, diseases characterized by reduced intracranial compliance, hence diminished pulsations, can be related to the glymphatic pathway. ${ }^{29}$ An important disease in this context is idiopathic normal pressure hydrocephalus (INPH), which is characterized by gait ataxia, urinary incontinence and dementia. The link between INPH and the glymphatic system could explain the high association between this disease and Alzheimer, ${ }^{30}$ as well as why dementia is a strong feature of INPH.

Shunt surgeries are the best option for most cases of INPH, with no conservative management being fully effective. ${ }^{31}$ The clinical presentation of INPH, nonetheless, is not sufficient to indicate surgery, as each symptom can result from several pathologies. Therefore, predictive tests, such as the CSF tap test, are necessary to determine the responsiveness of the shunt. ${ }^{32}$ In 2017, Ringstad et al published a study ${ }^{33}$ that aimed to assess CSF flow characteristics and glymphatic function in 15 patients with INPH, comparing them with 8 reference subjects. Until then, this assessment had been limited to rodents. ${ }^{34}$

Table 2 Glymphatic system malfunctions related to neurodegenerative diseases

\begin{tabular}{|l|l|}
\hline Diseases & Glymphatic system malfunction \\
\hline Alzheimer disease & $\begin{array}{l}\text { The disorder is characterized by tau and amyloid- } \beta \text { accumulation, leading to } \\
\text { diminished glymphatic efficiency }\end{array}$ \\
\hline Normal pressure hydrocephalus & $\begin{array}{l}\text { Glymphatic function is reduced in mice with normal pressure hydrocephalus } \\
\text { due to reduced arterial pulsations }\end{array}$ \\
\hline Glaucoma & Raised intraocular pressure leads to amyloid- $\beta$ and tau accumulation ${ }^{43,44}$ \\
\hline Traumatic brain injury & $\begin{array}{l}\text { Glymphatic pathway function can be reduced up to } 60 \% \text { after a traumatic brain injury, } \\
\text { for at least one month, enabling the accumulation of tau and other proteins }\end{array}$ \\
\hline
\end{tabular}


Intrathecal contrast (gadobutrol) served as a cerebrospinal fluid tracer, and T1-weighted magnetic resonance imaging (MRI) exams revealed delayed glymphatic clearance in INPH patients. The study by Ringstad et al also reaffirmed the paramount role of intracranial pulsations for glymphatic transport, and showed a glymphatic peak of enhancement overnight, suggesting increased glymphatic function during sleep. Finally, the study ${ }^{33}$ presented the glymphatic MRI as a potential mechanism to evaluate the metabolic function of the brain, a subject also debated in another article. ${ }^{35}$

\section{Glaucoma}

Glaucoma, one of the leading causes of irreversible blindness, is another complex neurodegenerative disease. ${ }^{36,37}$ Both the pressure and composition of the CSF surrounding the optic nerve influence the pathogenesis of this disease. ${ }^{38-40}$

A link between glaucoma and Alzheimer disease was suggested once some studies associated $A \beta$ accumulation to the apoptosis of retinal ganglion cells. ${ }^{41-43}$ Chronically raised intraocular pressure leads to caspase-3-mediated irregular processing of the amyloid precursor protein, hence increasing $A \beta$ to a neurotoxic level. It was also demonstrated that targeting $A \beta$ and blocking its effects represents an efficient treatment strategy for glaucoma. ${ }^{43}$ Additionally, Yoneda et al associated glaucoma and tau accumulation. ${ }^{44}$

The second cranial nerve is an extension of the CNS itself; ${ }^{45}$ therefore, it has a glymphatic system. ${ }^{46}$ Ergo, the aforementioned treatment implications to Alzheimer disease could possibly be applied to glaucoma.

\section{Traumatic Brain Injury}

Traumatic brain injury (TBI) is an established risk factor for the development of dementia, ${ }^{47}$ with neurofibrillary tangles of tau protein commonly present in the posttraumatic brain. ${ }^{6}$ It was observed that following brain injury there is a significant release of tau into the ISF and CSF, possibly due to the axonal damage. ${ }^{48-50} \mathrm{~A}$ study by Iliff et al added that a large proportion of interstitial monomeric tau is cleared from the cortex by bulk flow along the white matter tracks and perivascular system. ${ }^{6}$

As previously mentioned, the glymphatic system has a pivotal role in the clearance of interstitial solutes, including tau and $\mathrm{A} \beta$. After $\mathrm{TBI}$, it was demonstrated that the glymphatic pathway function could be reduced by $\sim 60 \%$, an impairment that persisted for at least one month after the trauma, explaining the brain's vulnerability to tau aggregation and subsequent neurodegeneration. ${ }^{6}$

\section{Conclusion}

Despite the research advances, there is still much to find out about the glymphatic system, which remains a novel concept. It is important to recognize its existence, with all its implications, such as the pathway's association with the development of neurodegenerative diseases. In this context, further elucidation is necessary to enable new perspectives for the development of novel therapeutic and diagnostic strategies for these disorders. For instance, although recent studies reinforce the idea that a perivascular system exists in the eye and optic nerve, the glymphatic hypothesis of glaucoma has not yet been scientifically proved. The relationship of Alzheimer disease and normal pressure hydrocephalus to the pathway, likewise, is not fully comprehended, and further investigation is needed. It is also necessary to understand how alterations in awareness state, body posture and exercise habits can influence protein clearance, to benefit the patient. A multidisciplinary discussion, with physiotherapists, neurologists and neurosurgeons, is mandatory in order to achieve better outcomes when managing glymphatic disorders.

\section{Conflicts of Interest}

The authors have no conflicts of interest to disclose.

\section{References}

1 Nedergaard M. Neuroscience. Garbage truck of the brain. Science 2013;340(6140):1529-1530

2 Benveniste H, Lee H, Volkow ND. The Glymphatic Pathway.

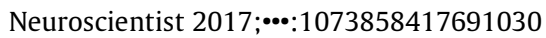

3 Nedergaard M, Goldman SA. Brain Drain. Sci Am 2016;314(03): 44-49

4 Cserr HF, Cooper DN, Milhorat TH. Flow of cerebral interstitial fluid as indicated by the removal of extracellular markers from rat caudate nucleus. Exp Eye Res 1977;25(Suppl):461-473

5 Rennels ML, Gregory TF, Blaumanis OR, Fujimoto K, Grady PA. Evidence for a 'paravascular' fluid circulation in the mammalian central nervous system, provided by the rapid distribution of tracer protein throughout the brain from the subarachnoid space. Brain Res 1985;326(01):47-63

6 Iliff JJ, Chen MJ, Plog BA, et al. Impairment of glymphatic pathway function promotes tau pathology after traumatic brain injury. J Neurosci 2014;34(49):16180-16193

7 Iliff JJ, Wang M, Liao Y, et al. A paravascular pathway facilitates CSF flow through the brain parenchyma and the clearance of interstitial solutes, including amyloid $\beta$. Sci Transl Med 2012;4 (147):147ra111

8 Murlidharan G, Crowther A, Reardon RA, Song J, Asokan A. Glymphatic fluid transport controls paravascular clearance of AAV vectors from the brain. JCI Insight 2016;1(14):e88034

9 Bradley WG Jr. CSF Flow in the Brain in the Context of Normal Pressure Hydrocephalus. AJNR Am J Neuroradiol 2015;36(05): 831-838

10 Franceschi C, Campisi J. Chronic inflammation (inflammaging) and its potential contribution to age-associated diseases. J Gerontol A Biol Sci Med Sci 2014;69(Suppl 1):S4-S9

11 Di Benedetto S, Müller L, Wenger E, Düzel S, Pawelec G. Contribution of neuroinflammation and immunity to brain aging and the mitigating effects of physical and cognitive interventions. Neurosci Biobehav Rev 2017;75:114-128

12 Barrientos RM, Kitt MM, Watkins LR, Maier SF. Neuroinflammation in the normal aging hippocampus. Neuroscience 2015;309:84-99

13 Ren $\mathrm{H}$, Luo C, Feng Y, et al. Omega-3 polyunsaturated fatty acids promote amyloid- $\beta$ clearance from the brain through mediating the function of the glymphatic system. FASEB J 2017;31(01): 282-293

14 Raha AA, Henderson JW, Stott SR, et al. Neuroprotective Effect of TREM-2 in Aging and Alzheimer's Disease Model. J Alzheimers Dis 2017;55(01):199-217

15 Eckert A, Hauptmann S, Scherping I, et al. Oligomeric and fibrillar species of beta-amyloid (A beta 42) both impair mitochondrial function in P301L tau transgenic mice. J Mol Med (Berl) 2008;86 (11):1255-1267 
16 Rijal Upadhaya A, Capetillo-Zarate E, Kosterin I, et al. Dispersible amyloid $\beta$-protein oligomers, protofibrils, and fibrils represent diffusible but not soluble aggregates: their role in neurodegeneration in amyloid precursor protein (APP) transgenic mice. Neurobiol Aging 2012;33(11):2641-2660

17 Iliff JJ, Wang M, Zeppenfeld DM, et al. Cerebral arterial pulsation drives paravascular CSF-interstitial fluid exchange in the murine brain. J Neurosci 2013;33(46):18190-18199

18 Kress BT, Iliff JJ, Xia M, et al. Impairment of paravascular clearance pathways in the aging brain. Ann Neurol 2014;76(06):845-861

19 Xie L, Kang H, Xu Q, et al. Sleep drives metabolite clearance from the adult brain. Science 2013;342(6156):373-377

20 Malow BA. Sleep deprivation and epilepsy. Epilepsy Curr 2004;4 (05):193-195

21 Stickgold R. Neuroscience: a memory boost while you sleep. Nature 2006;444(7119):559-560

22 Schneider GH, von Helden GH, Franke R, Lanksch WR, Unterberg A. Influence of body position on jugular venous oxygen saturation, intracranial pressure and cerebral perfusion pressure. Acta Neurochir Suppl (Wien) 1993;59:107-112

23 Brosnan RJ, Steffey EP, LeCouteur RA, Imai A, Farver TB, Kortz GD. Effects of body position on intracranial and cerebral perfusion pressures in isoflurane-anesthetized horses. J Appl Physiol (1985) 2002;92(06):2542-2546

24 Lee H, Xie L, Yu M, et al. The Effect of Body Posture on Brain Glymphatic Transport. J Neurosci 2015;35(31):11034-11044

25 He XF, Liu DX, Zhang Q et al. Voluntary Exercise Promotes Glymphatic Clearance of Amyloid Beta and Reduces the Activation of Astrocytes and Microglia in Aged Mice. Front Mol Neurosci 2017; $10: 144$

26 Reitz C, Brayne C, Mayeux R. Epidemiology of Alzheimer disease. Nat Rev Neurol 2011;7(03):137-152

27 Bloom GS. Amyloid- $\beta$ and tau: the trigger and bullet in Alzheimer disease pathogenesis. JAMA Neurol 2014;71(04):505-508

28 Honig LS, Vellas B, Woodward M, et al. Trial of Solanezumab for Mild Dementia Due to Alzheimer's Disease. N Engl J Med 2018; 378(04):321-330

29 Eide PK, Sorteberg W. Diagnostic intracranial pressure monitoring and surgical management in idiopathic normal pressure hydrocephalus: a 6-year review of 214 patients. Neurosurgery 2010;66(01):80-91

30 Cabral D, Beach TG, Vedders L, et al. Frequency of Alzheimer's disease pathology at autopsy in patients with clinical normal pressure hydrocephalus. Alzheimers Dement 2011;7(05):509-513

31 Williams MA. Comment: the trouble with " $n$ " in normal-pressure hydrocephalus. Neurology 2014;82(15):1350

32 Williams MA, Malm J. Diagnosis and Treatment of Idiopathic Normal Pressure Hydrocephalus. Continuum (Minneap Minn) 2016;22(2 Dementia):579-599

33 Ringstad G, Vatnehol SAS, Eide PK. Glymphatic MRI in idiopathic normal pressure hydrocephalus. Brain 2017;140(10):2691-2705
34 Iliff JJ, Lee H, Yu M, et al. Brain-wide pathway for waste clearance captured by contrast-enhanced MRI. J Clin Invest 2013;123(03): 1299-1309

35 Eide PK, Ringstad G. MRI with intrathecal MRI gadolinium contrast medium administration: a possible method to assess glymphatic function in human brain. Acta Radiol Open 2015;4(11): 2058460115609635

36 Wostyn P, De Groot V, Van Dam D, Audenaert K, De Deyn PP. Senescent changes in cerebrospinal fluid circulatory physiology and their role in the pathogenesis of normal-tension glaucoma. Am J Ophthalmol 2013;156(01):5-14.e2

37 Wostyn P, Van Dam D, Audenaert K, Killer HE, De Deyn PP, De Groot V. A new glaucoma hypothesis: a role of glymphatic system dysfunction. Fluids Barriers CNS 2015;12:16

38 Berdahl JP, Fautsch MP, Stinnett SS, Allingham RR. Intracranial pressure in primary open angle glaucoma, normal tension glaucoma, and ocular hypertension: a case-control study. Invest Ophthalmol Vis Sci 2008;49(12):5412-5418

39 Ren R, Jonas JB, Tian G, et al. Cerebrospinal fluid pressure in glaucoma: a prospective study. Ophthalmology 2010;117(02):259-266

40 Killer HE, Miller NR, Flammer J, et al. Cerebrospinal fluid exchange in the optic nerve in normal-tension glaucoma. $\mathrm{Br} \mathrm{J} \mathrm{Ophthalmol}$ 2012;96(04):544-548

41 McKinnon SJ, Lehman DM, Kerrigan-Baumrind LA, et al. Caspase activation and amyloid precursor protein cleavage in rat ocular hypertension. Invest Ophthalmol Vis Sci 2002;43(04):1077-1087

42 McKinnon SJ. Glaucoma: ocular Alzheimer's disease? Front Biosci 2003;8:s1140-s1156

43 Guo L, Salt TE, Luong V, et al. Targeting amyloid-beta in glaucoma treatment. Proc Natl Acad Sci U S A 2007;104(33):13444-13449

44 Yoneda S, Hara H, Hirata A, Fukushima M, Inomata Y, Tanihara H. Vitreous fluid levels of beta-amyloid((1-42)) and tau in patients with retinal diseases. Jpn J Ophthalmol 2005;49(02):106-108

45 McCaa CS. The eye and visual nervous system: anatomy, physiology and toxicology. Environ Health Perspect 1982;44:1-8

46 Wostyn P, De Groot V, Van Dam D, Audenaert K, Killer HE, De Deyn PP. The Glymphatic Hypothesis of Glaucoma: A Unifying Concept Incorporating Vascular, Biomechanical, and Biochemical Aspects of the Disease. BioMed Res Int 2017;2017:5123148

47 Guo Z, Cupples LA, Kurz A, et al. Head injury and the risk of AD in the MIRAGE study. Neurology 2000;54(06):1316-1323

48 Morris M, Maeda S, Vossel K, Mucke L. The many faces of tau. Neuron 2011;70(03):410-426

49 Magnoni S, Esparza TJ, Conte V, et al. Tau elevations in the brain extracellular space correlate with reduced amyloid- $\beta$ levels and predict adverse clinical outcomes after severe traumatic brain injury. Brain 2012;135(Pt 4):1268-1280

50 Tsitsopoulos PP, Marklund N. Amyloid- $\beta$ Peptides and Tau Protein as Biomarkers in Cerebrospinal and Interstitial Fluid Following Traumatic Brain Injury: A Review of Experimental and Clinical Studies. Front Neurol 2013;4:79 